\title{
Airway obstruction can be better predicted using Global Lung Function Initiative spirometry reference equations in Marfan syndrome
}

\author{
A. M. KOLONICS-FARKAS ${ }^{1 *}$ (D, Z. KOVATS $^{1}$, A. BOHACS ${ }^{1}$, B. ODLER ${ }^{1,2}$, \\ K. BENKE ${ }^{3,4}$, B. $A G^{3,4,5}$, Z. SZABOLCS $^{3,4}$ and V. MÜLLER ${ }^{1}$
}

${ }^{1}$ Department of Pulmonology, Semmelweis University, Budapest, Hungary

${ }^{2}$ Division of Nephrology, Department of Internal Medicine, Medical University of Graz, Graz, Austria

${ }^{3}$ Heart and Vascular Center, Semmelweis University, Budapest, Hungary

${ }^{4}$ Hungarian Marfan Foundation, Budapest, Hungary

${ }^{5}$ Department of Pharmacology and Pharmacotherapy, Semmelweis University, Budapest, Hungary

Received: May 7, 2020 - Accepted: August 29, 2020

Published online: March 26, 2021

(C) 2021 The Author(s)

\section{ABSTRACT}

Marfan syndrome is a genetic disorder of the connective tissue, including involvement of the lungs.

Pulmonary function test was performed in 32 asymptomatic adult Marfan patients using European Community for Coal and Steel (ECCS) and Global Lung Function Initiative (GLI) reference values.

Using GLI equations for reference, significantly lower lung function values were noted for forced vital capacity $(\mathrm{FVC})(87.0 \pm 16.6 \%$ vs. $97.1 \pm 16.9 \% ; P<0.01)$ and forced expiratory volume in the first second (FEV1) $(79.6 \pm 18.9 \%$ vs. $88.0 \pm 19.1 \%$; $P<0.01)$ predicted compared to ECCS. Obstructive ventilatory pattern was present in $25 \%$ of the cases when calculating with GLI lower limit of normal (LLN), and it was significantly more common in men as compared to women $(n=6,50 \%$ vs. $n=2,10 \%$; $P=0.03)$.

GLI is more suitable to detect early ventilatory changes including airway obstruction in young patients with special anatomic features, and should be used as a standard way of evaluation in asymptomatic Marfan population.

* Corresponding author. Department of Pulmonology, Semmelweis University, Budapest, Hungary Tömő utca 25-29, Budapest, 1083 Hungary; Tel.: +36 1 3559733; Fax: +36 1 214-2498; E-mail: kolonics-farkas.abigel@med. semmelweis-univ.hu 


\section{KEYWORDS}

Marfan syndrome, lung function, spirometry, reference values, Global Lung Function Initiative

\section{INTRODUCTION}

Marfan syndrome (MFS) is an autosomal dominant connective tissue disorder, mainly characterized by vascular and skeletal manifestations, including common involvement of the lungs [1]. The diagnosis of the syndrome is based on the revised Ghent nosology [2]. Pleuropulmonary structural abnormalities are associated with frequent respiratory symptoms in MFS patients [3].

Lung function (LF) values are affected by thoracic structures, airways, lung parenchyma, pleura and muscle function. [4] Spirometry is significantly influenced by subject cooperation, affected by technical factors. Thus, measurements need to be performed according to a strict protocol [4]. In 1960 the European Community for Coal and Steel (ECCS) was the first organization to issue recommendations for spirometry and released equations for calculations of reference values [5]. In Hungary the ECCS calculations were used until recently, where height and age are major determinants of LF reference equations, and corrections are necessary for height in special patient populations [3]. Several data supported the need for more appropriate reference values for spirometry; in 2012, Quanjer et al. published new spirometric prediction equations that include appropriate age-dependent lower limits of normal (LLN), which can also be applied to both sexes and different ethnic groups (Global Lung Function Initiative 2012-GLI) [6].

The difficulty of appropriate evaluation of spirometric data is known in many lung diseases. One example including possible false LF interpretation is the forced expiratory volume in the first second (FEV1)/forced vital capacity (FVC) ratio value (FEV1/FVC), especially in younger adults $[7,8]$.

Reference values used in patients with special body measures characteristic of MFS (these patients show excess in linear growth and are subsequently taller than predicted) can be misleading, and comparative measures are lacking. In this study we compared ECCS and GLI LF parameters in asymptomatic Marfan patients of both sexes.

\section{MATERIALS AND METHODS}

\section{Participants}

Our investigation had a cross-sectional design. We invited patients from the National Marfan Registry [9].

All pulmonary examinations were voluntary; the participants of the Registry received invitation letters to join the study. All included adult patients signed informed consent for participation. The LF measurements were carried out in the Department of Pulmonology, Semmelweis University, Budapest, Hungary between 2015 and 2017. Exclusion criteria included patients with known coexistent pulmonary disease and the use of any pulmonary medications, major thoracic surgery within six months before the check-up, and patients who presented with 
acute respiratory symptoms (dyspnea, cough, sputum, and chest paint that was unusual in comparison to the chest complaints the patients had in the everyday life due to their chest deformities).

\section{Measurements}

Detailed clinical and medication history, data regarding anthropometric features (height, bodyweight) were collected. LF measurements were performed by means of electronic spirometer and body plethysmography (PDD-301/s, Piston, Budapest, Hungary) according to the European Respiratory Society (ERS) and American Thoracic Society (ATS) guidelines. Three technically acceptable maneuvers were performed and the highest value was used [4]. The patients did not receive short-acting bronchodilators before spirometry, and a reversibility test was not performed. As baseline reference values we used the database of the ECCS set by the spirometry manufacturer [10].

The recalculation of the LF values with GLI equations was performed with the "GLI-2012 Desktop Software for Individual Calculations" software [11]. The necessary information for the recalculation were sex, ethnicity, age, height, FVC, and FEV1 values given in liters.

In the absence of aortic root aneurism or ectopia lentis, the presence of a fibrillin-1 gene mutation or positive systemic score is required for the diagnosis of MFS [12]. The systemic score provides information about the possible progression of the disease (Table 1) [13]. Systemic involvement can be determined if the score is $\geq 7$ points and was calculated in each case.

The study protocol was approved by the Ethical Committee of the Semmelweis University Regional and Institutional Committee of Science and Research Ethics (TUKEB 165/2016).

\section{Statistical analysis}

Statistical analysis was performed using GraphPad Prism 8 for Windows (La Jolla, California, USA). Data are presented as mean and standard deviation for continuous data and as median and range for categorical data. Differences between groups for parametric data were compared using Student's $t$-test, whereas Fisher's exact test was applied for analyzing nonparametric data. To observe the possible relation between variables, we additionally performed linear regression. In all cases $P<0.05$ was considered statistically significant.

\section{RESULTS}

Patient characteristics are summarized in Table 2. Regarding Ghent criteria, most of the patients had mitral valve prolapse, myopia, skin striae, and skeletal deformities (Table 1). Clinical data and parameters of individual patients are presented in Fig. 1 . The vast majority of the patients never smoked. There were significantly more men than women in the smoker group $(P=0.02)$.

The summary of LF results is shown in Table 3. No significant differences were present between sexes regarding FVC\% and FEV1\% using ECCS. When calculating with GLI, lower $\mathrm{FVC} \%$ and $\mathrm{FEV} 1 \%$ values could be observed, however the difference was not significant as compared to ECCS results. With the use of GLI LLN we were able to confirm abnormal FVC\% values in twice as many cases as with the use of ECCS, and there were also below threshold 
Table 1. Calculation of the systemic score in MFS [13]

\begin{tabular}{lcc}
\hline Symptom & Score & Number of affected patients, $n(\%)$ \\
\hline Wrist and thumb sign & 3 & $25(78.1)$ \\
Wrist or thumb sign & 1 & $28(87.5)$ \\
Pectus carinatum deformity & 2 & $15(46.9)$ \\
Pectus excavatum or chest asymmetry & 1 & $14(43.8)$ \\
Hindfoot deformity & 2 & $5(15.6)$ \\
Plain pes planus & 1 & $14(43.8)$ \\
Pneumothorax & 2 & $2(6.3)$ \\
Dural ectasia & 2 & $2(6.3)$ \\
Protrusio acetabuli & 2 & $0(0)$ \\
Reduced US/LS AND increased arm/ & 1 & $8(25.0)$ \\
$\quad$ height AND no severe scoliosis & & \\
Scoliosis or thoracolumbar kyphosis & 1 & $25(78.1)$ \\
Reduced elbow extension & 1 & $8(25.0)$ \\
Facial features (3/5) (dolichocephaly, & 1 & $4(12.5)$ \\
$\quad$ enophtalmos, downslanting palpebral & & \\
$\quad$ fissures, malar hyoplasia, & & \\
$\quad$ retrognathia) & & $21(65.6)$ \\
Skin striae & 1 & $21(65.6)$ \\
Myopia $>3$ diopters & 1 & $26(81.2)$
\end{tabular}

Table 2. Patient characteristics

\begin{tabular}{lcccc}
\hline & & & $P$-value \\
& All patients $(n=32)$ & Men $(n=12)$ & Women $(n=20)$ & Men vs. Women \\
\hline Age (years) & $36.4 \pm 11.8$ & $34.7 \pm 11.7$ & $37.4 \pm 12.1$ & n.s. \\
Weight & $71.4 \pm 17.0$ & $81.3 \pm 19.2$ & $65.56 \pm 12.7$ & 0.02 \\
Height $(\mathrm{cm})$ & $183.4 \pm 10.5$ & $192.3 \pm 9.1$ & $177.6 \pm 6.5$ & $P<0.01$ \\
BMI $\left(\mathrm{kg} / \mathrm{m}^{2}\right)$ & $21.2 \pm 4.1$ & $21.9 \pm 5.0$ & $20.8 \pm 3.5$ & n.s. \\
\hline
\end{tabular}

KEY: $\mathrm{BMI}=$ body mass index.

Data are presented as mean \pm standard deviation.

values regarding FEV1\% (Fig. 1, individual data). Using systemic scores patients were divided into 2 groups: one group without ( $<7$ points) and the other with systemic involvement $(\geq 7$ points). We compared FEV1/FVC using both ECCS and GLI for the 2 groups. In patients with systemic involvement the FEV1/FVC values were significantly lower when using GLI as compared to ECCS (Fig. 2). The relationship between the systemic score and FEV1/FVC values did not confirm association independent of the reference equation used ( $P>0.05$ in all cases). However, GLI seemed to be more sensitive in showing obstructive ventilatory pattern in low systemic score patients (Fig. 3). Airway obstruction appeared significantly more frequently 

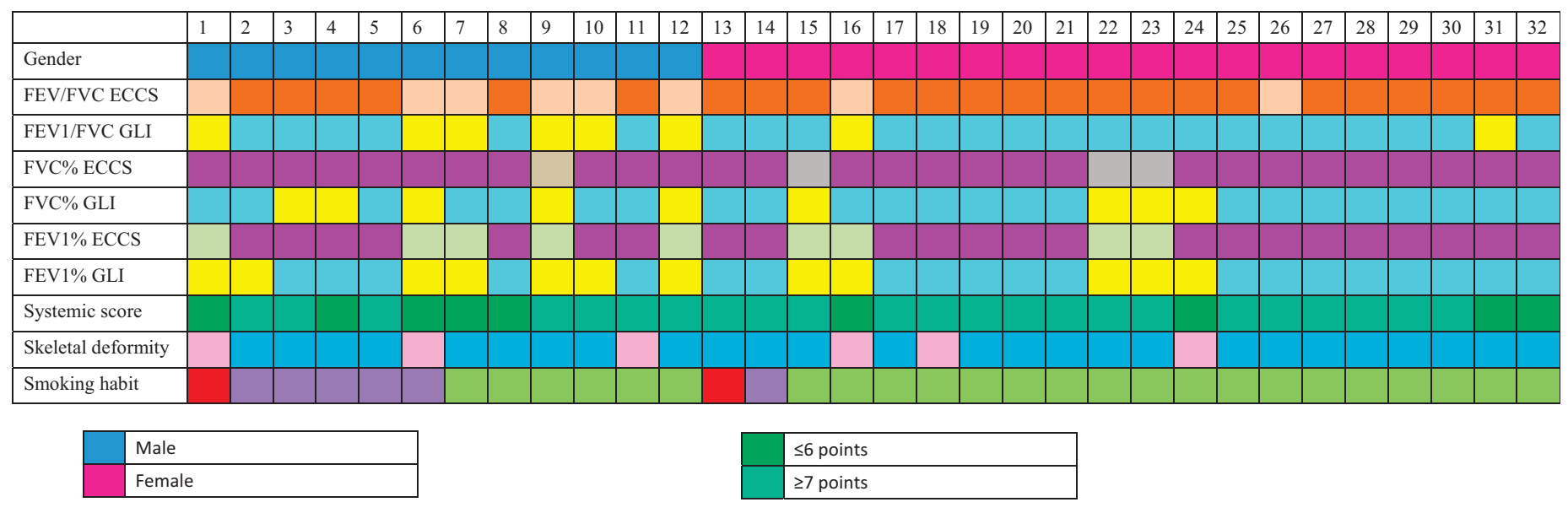

\begin{tabular}{|l|l|}
\hline & $\geq 70 \%$ \\
\hline & $<70 \%$ \\
\hline & $<$ LLN \\
\hline & $\geq \mathrm{LLN}$ \\
\hline & $<80 \%$ \\
\hline & $\geq 80 \%$ \\
\hline
\end{tabular}

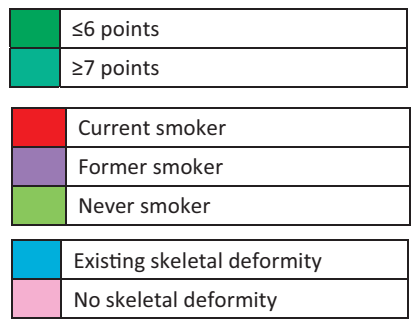

Fig. 1. Graphic summary of individual clinical data.

KEY: ECCS = European Community for Coal and Steel, FEV1 = Forced Expiratory Volume in the first second, FVC = Forced Vital Capacity, GLI $=$ Global Lung Initiative, LLN $=$ lower limit of normal 
Table 3. Lung function parameters using ECCS and GLI equations in Marfan patients

\begin{tabular}{|c|c|c|c|c|c|}
\hline & & $\begin{array}{l}\text { All patients } \\
(n=32)\end{array}$ & $\begin{array}{c}\text { Men } \\
(n=12)\end{array}$ & $\begin{array}{l}\text { Women } \\
(n=20)\end{array}$ & $\begin{array}{l}P \text {-value } \\
\text { Men vs. } \\
\text { Women }\end{array}$ \\
\hline \multirow{3}{*}{$\mathrm{FVC} \%$} & ECCS (\%) & $97.1 \pm 16.9$ & $93.4 \pm 12.4$ & $99.3 \pm 19.0$ & n.s. \\
\hline & GLI (\%) & $87.0 \pm 16.6^{*}$ & $82.7 \pm 15.5^{*}$ & $89.4 \pm 17.1^{*}$ & n.s. \\
\hline & $<\mathrm{LLN}$ GLI, $n(\%)$ & $9(28)$ & $5(42)$ & $4(20)$ & n.s. \\
\hline \multirow[t]{3}{*}{ FEV1\% } & ECCS (\%) & $88.0 \pm 19.1$ & $83.4 \pm 17.9$ & $90.7 \pm 18.1$ & n.s. \\
\hline & GLI (\%) & $79.6 \pm 18.9^{*}$ & $78.7 \pm 15.6 \S$ & $80.2 \pm 21.2^{*}$ & n.s. \\
\hline & $<\mathrm{LLN}$ GLI, $n(\%)$ & $11(34)$ & $6(50)$ & $5(25)$ & n.s. \\
\hline \multirow[t]{3}{*}{ FEV1/FVC } & ECCS & $77.1 \pm 8.7$ & $73.1 \pm 9.3$ & $79.5 \pm 7.1$ & 0.04 \\
\hline & GLI (\%) & $71.0 \pm 2.7$ & $70.2 \pm 2.4$ & $71.5 \pm 2.8$ & n.s. \\
\hline & $<\mathrm{LLN}$ GLI, $n(\%)$ & $8(25)$ & $6(50)$ & $2(10)$ & 0.03 \\
\hline
\end{tabular}

KEY: ECCS $=$ European Community for Coal and Steel, FEV1 $=$ Forced Expiratory Volume in the first second, FVC $=$ Forced Vital Capacity, GLI $=$ Global Lung Initiative, LLN $=$ lower limit of normal. n.s. $=$ not significant $(P$-value $>0.05)$.

* $=P$-value $<0.01$ vs. ECCS, $\S=P$-value $=0.02$ vs. ECCS.

Data are presented as mean \pm standard deviation.

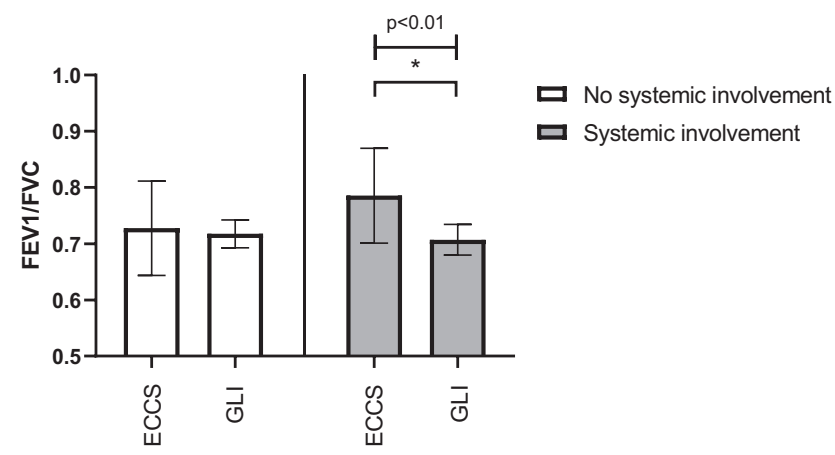

Fig. 2. FEV1/FVC values calculated with ECCS and GLI in MFS patients with no systemic involvement and in MFS patients with systemic involvement.

KEY: ECCS = European Community for Coal and Steel, FEV1 = Forced Expiratory Volume in the first second, FVC $=$ Forced Vital Capacity, GLI $=$ Global Lung Initiative, MFS = Marfan syndrome

with the use of GLI LLN in men as compared to women. Obstruction severity expressed by FEV $1 \%$ predicted $(<80 \%$ reference or $<$ LLN) was more pronounced in men using GLI equations. 


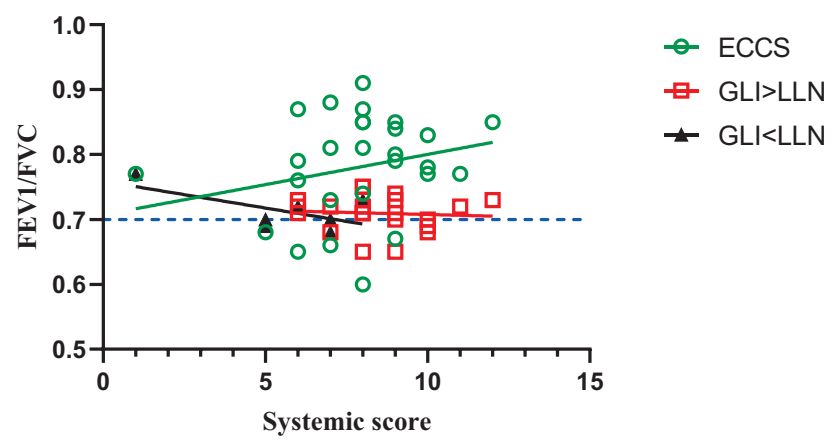

Fig. 3. Association between MFS systemic scores and FEV1/FVC when calculating with ECCS and GLI reference equations. The blue broken line marks 70\% of FEV1/FVC.

KEY: ECCS $=$ European Community for Coal and Steel, FEV1 = Forced Expiratory Volume in the first second, FVC $=$ Forced Vital Capacity, GLI = Global Lung Initiative, LLN = lower limit of normal, MFS $=$ Marfan syndrome

\section{DISCUSSION}

In our study $25 \%$ of asymptomatic young Marfan patients were identified with airway obstruction, $28 \%$ with restrictive ventilatory pattern including $9 \%$ with mixed ventilatory disorder. The use of GLI LLN for FEV1/FVC appeared to be more appropriate in the definition of subclinical airway obstruction, especially in MFS men.

LF testing plays an indispensable role in respiratory care. When interpreting spirometric data, measured values are expressed as percent of predicted. This method is probably applied after the recommendation of Bates and Christie, who stated that a useful general rule is that a deviation of $20 \%$ from the predicted normal value is probably significant [14]. Considering $80 \%$ of predicted as the LLN is often accepted, although, it is only valid if the scatter around the predicted value is proportional to the value: small if the predicted value is small, and proportionally larger if the predicted value is large [5]. However, spirometry data lack proportionality, and this leads to incorrect interpretation of the results [6, 15-19]. The need of more precise LF calculations considering more aspects arose as published by Quanjer et al. in 2012. Diagnostic thresholds must account for age- and gender-related changes for $\operatorname{LF}[20,21]$. Potential misidentification of respiratory disease, especially in aging populations is a major public health concern. Previous studies on 10131 COPD patients (COPDGene) highlight the clinical importance of GLI-defined Z-score of -1.64 defining LLN at the 5th percentile of distribution [15]. GLI-defined normal values suggested the absence of clinically meaningful respiratory disease compared to GOLD spirometry classification. Discordant classification by GOLD but normal LLN might result in misidentification of emphysema as COPD. Additionally, the clinical importance of GLI-defined spirometric restrictive pattern was associated with higher odds of having dyspnea and poor exercise performance. In the background cardiovascular mechanism, respiratory muscle weakness, obesity and kyphoscoliosis were identified as possible contributors. 
In our study individual presentation of LF values using the two reference equations were discordant in $6.3 \%$, whereas concordant data were seen in $21.9 \%$ for airway obstruction. FVC decline as a marker of restrictive ventilatory disorder was only present in 4 patients using ECCS, whereas $28.1 \%(n=9)$ were under LLN using GLI. Identification of mixed ventilatory disorder was more common when using GLI 9.4\% $(n=3)$.

Several prediction equations are based on data collected decades ago, leading to inaccurate LF results in many patient groups [5]. It was considered too difficult to calculate the LLN for the FEV1/FVC, thus the Global Initiative for Chronic Obstructive Lung Disease (GOLD) group decided that it was easier to adopt a fixed LLN of 0.7. Also, a lot of criticism has been published about the unscientific method and the lack of evidence that obstructive lung disease using fixed LLN can be properly diagnosed $[6,22,23]$. This criterion might lead to a false negative finding regarding the prevalence of obstructive lung diseases, especially in younger individuals, whereas to higher prevalence in older patients [5].

GLI equations use a unified method interpreting LF in different races across all ages and sexes [6]. In adults FEV1/FVC ratios differ from those of GLI as compared to ECCS [24]. This is mainly due to the fact that GLI equations take into account that the ratio is inversely related to standing height, whereas ECCS equations take only age into account. This finding is also supported by the study of Kuster et al. [25]. Thus, the ECCS-predicted values need to be abandoned and the GLI reference equations should be preferred, as it has already been validated in several studies $[26,27]$.

Patients with special body proportions like MFS patients may have false positive or false negative values if predictions are biased by height. Our former study on a larger cohort of MFS patients - including symptomatic participants and focusing on major thoracic surgery confirmed the presence of airway obstruction and the significance of the use of arm span for height correction to precisely evaluate LF changes in this special patient group involving patients with significant scoliosis [3]. In this study we applied two methods to calculate the LFs, namely ECCS and GLI, and the results were more consistent when using GLI. This agrees with the findings of Stanojevic et al., and is also subsequently endorsed by the ATS and other respiratory societies worldwide [6]. It is important to note that MFS patients are more prone to airway obstruction, and FEV1\% using GLI was more sensitive to detect early changes in asymptomatic, young patients, especially in men. Fragoso et al. observed that GLI often defined normal (>LLN) spirometry in patients classified as COPD by GOLD [20].

As in MFS the patients have special physical features, sensitive spirometric reference equations are crucial - particularly due to the frequent need of surgeries because of cardiovascular and skeletal abnormalities. Marfan patients often have kyphoscoliosis and emphysema resulting in a mixed (restrictive-obstructive) ventilatory disorder. Our data confirmed that GLI is more sensitive to detect airway obstruction in patients with unique anatomic properties and should be the standard way of evaluation as compared to height correction in MFS. With the application of GLI reference equations the daily clinical practice in respiratory care can be eased and it can be applied for patient populations with unusual physical characteristics.

A limitation of our study is that while including asymptomatic patients, in-depth analysis of possible reduction of exercise capacity as a marker of coexisting emphysema might have been missed. GLI-defined airway obstruction is often associated with emphysema, according to the COPDGene study, where mild obstruction was associated with $\sim 4.4 \%$ of emphysema and $19.1 \%$ of gas trapping [20]. A future imaging study is planned to evaluate the extent of emphysema and 
air trapping in these patients. Longitudinal evaluation of LF using GLI is also needed to assess the lung aging process in MFS.

Funding: This work was supported by the National Research, Development and Innovation Office of Hungary (NKFIH; NVKP-16-1-2016-0017), by the Higher Education Institutional Excellence Programme of the Ministry of Human Capacities in Hungary, within the framework of the Therapeutic Development thematic programme of the Semmelweis University and by the "New National Excellence Program of the Ministry of Human Capacities of Hungary" (ÚNKP17-3-I-SE-31 and ÚNKP-18-3-I-SE-69; BÁ).

\section{ACKNOWLEDGEMENTS}

We thank all the members of the Hungarian Marfan Foundation.

\section{REFERENCES}

1. Corsico AG, Grosso A, Tripon B, Albicini F, Gini E, Mazzetta A, et al. Pulmonary involvement in patients with marfan syndrome. Panminerva Med [Internet]. 2014 Jun; 56(2): 177-82 [cited 2016 Jan 24]. Available from: http://www.ncbi.nlm.nih.gov/pubmed/24994580.

2. Loeys BL, Dietz HC, Braverman AC, Callewaert BL, De Backer J, Devereux RB, et al. The revised Ghent nosology for the Marfan syndrome. 2010 [cited 2016 Aug 1]. Available from: http://jmg.bmj.com/content/47/ 7/476.full.html\#ref-list-1.

3. Kolonics-Farkas AM, Agg B, Benke K, Odler B, Bohacs A, Kovats Z, et al. Lung function changes are more common in marfan patients who need major thoracic surgery. Lung [Internet]. 2019; 197: 465-72. Available from: https://doi.org/10.1007/s00408-019-00236-1.

4. Miller MR, Hankinson J, Brusasco V, Burgos F, Casaburi R, Coates A, et al. Standardisation of spirometry. Eur Respir J [Internet]. 2005 Aug 1; 26(2): 319-38 [cited 2018 Feb 12]. Available from: http://erj.ersjournals. com/cgi/doi/10.1183/09031936.05.00034805.

5. Quanjer PH, Stanojevic S, Stocks J, Cole TJ. GLI-2012 reference values for spirometry GLI-2012 All-Age Multi-Ethnic Reference Values for Spirometry Advantages Consequences GLI-2012 reference values for spirometry Interpretation of spirometric data. [cited 2018 Feb 3]; Available from: http://www.ers-education. org/lrmedia/2012/pdf/266696.pdf.

6. Quanjer PH, Stanojevic S, Cole TJ, Baur X, Hall GL, Culver BH, et al. Multi-ethnic reference values for spirometry for the 3-95-yr age range: the global lung function 2012 equations. Eur Respir J 2012; 40(6): 1324-43.

7. Vaz Fragoso CA, McAvay G, Van Ness PH, Casaburi R, Jensen RL, MacIntyre N, et al. Phenotype of Normal spirometry in an aging population. Am J Respir Crit Care Med [Internet]. 2015 Oct; 192(7): 817-25 [cited 2020 Jul 13]. Available from: http://www.lungfunction.org/.

8. Wijnant SRA, de Roos E, Kavousi M, Stricker BH, Terzikhan N, Lahousse L, et al. Trajectory and mortality of preserved ratio impaired spirometry: the Rotterdam study. Eur Respir J [Internet]. 2020; 55(1): 1-12. Available from: http://dx.doi.org/10.1183/13993003.01217-2019.

9. Magyar Marfan Alapítvány [Internet]. [cited 2020 Jul 7]. Available from: https://marfan.hu/. 
10. Piston User Manual Supported Products. 2012 [cited 2018 Jan 13]. Available from: http://www.pistonmedical. com/Manuals/PDF/Spirometer_EN_2012-07-04.pdf.

11. GLI2012: Desktop Individual Calculator [Internet]. [cited 2018 Jan 13]. Available from: http://www.erseducation.org/guidelines/global-lung-function-initiative/spirometry-tools/desktop-individual-calculator.aspx.

12. Summary of Diagnostic Criteria | The Marfan Foundation [Internet]. [cited 2020 Jun 29]. Available from: https://www.marfan.org/dx/rules.

13. Loeys BL, Dietz HC, Braverman AC, Callewaert BL, De Backer J, Devereux RB, et al. The revised Ghent nosology for the Marfan syndrome. J Med Genet [Internet]. 2010 Jul 1; 47(7): 476-85 [cited 2020 Jun 29]. Available from: http://jmg.bmj.com/cgi/doi/10.1136/jmg.2009.072785.

14. Bates DV, Christie RV. Respiratory Function in Disease. 1st ed. W.B. Saunders; 1964. p. 91.

15. Stanojevic S, Wade A, Stocks J, Hankinson J, Coates AL, Pan H, et al. Reference ranges for spirometry across all ages. Am J Respir Crit Care Med [Internet]. 2008 Feb; 177(3): 253-60 [cited 2020 Jun 22]. Available from: http://www.

16. Sobol BJ, Weinheimer B. Assessment of Ventilatory Abnormality in the Asymptomatic Subject: An Exercise in Futility. Thorax 1966 Sep; 21(5): 445-9. http://dx.doi.org/10.1136/thx.21.5.445. PMID: 5969245; PMCID: PMC1019068.

17. Miller MR, Pincock AC. Predicted values: how should we use them? Thorax [Internet]. 1988 Apr 1; 43(4): 265-7 [cited 2020 Jun 22]. Available from: https://www.ncbi.nlm.nih.gov/pmc/articles/PMC461211/.

18. Lung function testing: selection of reference values and interpretative strategies. Am Rev Respir Dis [Internet]. 1991 Nov; 144(5): 1202-18 [cited 2020 Jun 22]. Available from: https://www.atsjournals.org/doi/abs/10.1164/ ajrccm/144.5.1202?journalCode $=$ arrd.

19. Miller MR, Quanjer PH, Swanney MP, Ruppel G, Enright PL. Interpreting lung function data using $80 \%$ predicted and fixed thresholds misclassifies more than $20 \%$ of patients. Chest [Internet]. 2011 Jan 1; 139(1): 52-9 [cited 2020 Jun 22]. Available from: https://pubmed.ncbi.nlm.nih.gov/20522571/.

20. Vaz Fragoso CA, McAvay G, Van Ness PH, Casaburi R, Jensen RL, MacIntyre N, et al. Phenotype of spirometric impairment in an aging population. Am J Respir Crit Care Med [Internet]. 2016 Apr; 193(7): 727-35 [cited 2020 Jun 28]. Available from: www.atsjournals.org.

21. Xie M, Cui L, Liu J, Wang W, Li J, Xiao W. Impacts of different spirometry reference equations and diagnostic criteria on the frequency of airway obstruction in adult people of North China. Int J Chron Obstruct Pulmon Dis [Internet]. 2020 Mar; 15:651-9 [cited 2020 Jul 10]. Available from: https://pubmed.ncbi.nlm.nih.gov/ 32273694/.

22. Quanjer PH, Enright PL, Miller MR, Stocks J, Ruppel G, Swanney MP, et al. The need to change the method for defining mild airway obstruction. Eur Respir J [Internet]. 2011 Mar 1; 37(3): 720-2 [cited 2020 Jun 22]. Available from: http://www.thepcrj.org.

23. Open Letter The need to change the method for defining mild airway obstruction. 2010 [cited 2020 Jun 22]. Available from: http://www.thepcrj.org.

24. Quanjer PH, Tammeling GJ, Cotes JE, Pedersen OF, Peslin R, Yernault JC. Lung volumes and forced ventilatory flows. Report working party standardization of lung function tests, European community for Steel and coal. Official statement of the European respiratory society. Eur Respir J Suppl [Internet]. 1993 Mar; 16: 5-40 [cited 2020 Jun 22]. Available from: http://www.ncbi.nlm.nih.gov/pubmed/7973051.

25. Kuster SP, Kuster D, Schindler C, Rochat MK, Braun J, Held L, et al. Reference equations for lung function screening of healthy never-smoking adults aged 18-80 years. Eur Respir J [Internet]. 2008 Apr 1; 31(4): 860-8 [cited 2020 Jul 14]. Available from: http://www.erj.ersjournals.com/current.shtml. 
26. Lum S, Bonner R, Kirkby J, Sonnappa S, Stocks J. S33 validation of the GLI-2012 multi-ethnic spirometry reference equations in London school children. Thorax [Internet]. 2012 Dec 19; 67(Suppl 2): A18.2-18 [cited 2020 Jun 22]. Available from: https://thorax.bmj.com/content/67/Suppl_2/A18.2.

27. Hall GL, Thompson BR, Stanojevic S, Abramson MJ, Beasley R, Coates A, et al. The Global Lung Initiative 2012 reference values reflect contemporary Australasian spirometry. Respirology [Internet]. 2012 Oct; 17(7): 1150-1 [cited 2020 Jun 22]. Available from: https://pubmed.ncbi.nlm.nih.gov/22849658/.

Open Access. This is an open-access article distributed under the terms of the Creative Commons Attribution 4.0 International License (https://creativecommons.org/licenses/by/4.0/), which permits unrestricted use, distribution, and reproduction in any medium, provided the original author and source are credited, a link to the CC License is provided, and changes - if any - are indicated. (SID_1) 